\title{
Freezing Index in Gryosurgery on the Prostate Gland
}

\author{
Yasuo Shiraiwa, Tsuneo Hirai, Tomonori Date and \\ SADATOSHI ICHIJO \\ Department of Urology, Fukushima Medical College, \\ Fukushima 960
}

Shtraiwa, Y., Hirai, T., Date, T. and IchiJo, S. Freezing Index in Cryosurgery on the Prostate Gland. Tohoku J. exp. Med., 1977, 123 (1), 49-56 - Cryosurgery has been performed on 18 patients with prostatic hypertrophy, and the following conclusions are reached: The quotient obtained by dividing the estimated weight of the prostate gland by the frozen weight obtained by an equation is called the freezing index, and this index can be introduced into the evaluation of the results of cryosurgery on the prostate gland. Cryosurgery was not markedly effective in cases of freezing indices over 0.76 , and the incidence of complications was high in cases of freezing indices not more than 0.5. The ideal freezing index obtained empirically was 0.6. No dysuria has recurred during past three years in the cases where cryosurgery was assessed satisfactory in effect within two to three months. cryosurgery; prostatic hypertrophy

During the ten years since the report by Gonder et al. (1966) on cryosurgery on the prostate gland, the clinical evaluation of this technique appears to have been established. However, when long-term observations are included, there is no definitive opinion about the relationship between the freezing time and the clincial effects. According to our idea that the freezing effect would improve in proportion to the freezing time to a certain extent, we examined the relationship between the size of hypertrophied prostate and the freezing time in terms of freezing index, and studied its correlation with the clinical effects.

\section{Procedures and Subjects}

Used in our cryosurgery was the model CE-4 unit manufactured by the Union Carbide, Linde Division, U.S.A., with a probe $21-\mathrm{Fr}$ in size and the freezing part $45 \mathrm{~mm}$ in length. As the subjects were selected 18 patients with prostatic hypertrophy. All the cases but one, in which cryosurgery was performed on the patient's desire, had been complicated by severe disturbances in the respiratory, cardiovascular and central nervous systems, and there were indications for cyrosurgery. The freezing technique currently employed greatly differs from that employed in the stage shortly after the introduction of the cryosurgery. In these days, the patient is instructed to take the lithotomy position after lumbar anesthesia; the bladder is punctured via the pubic area, and under observation with a trocar cystoscope the tip of the probe is inserted, and advanced to the bladder neck.

Received for publication, February 5, 1977.

Director: Prof. Y. Shiraiwa.

This paper is presented in commemoration of the 60th anniversary of the First Department of Surgery, Tohoku University School of Medicine. 


\section{RESULTS}

In Cases 1-5, 8 and 9 in which operations were done in the stage shortly after the introduction of the cryosurgery, sectio alta was used. In Cases 6 and 7, a blind procedure, and in Cases 10-18, cryosurgery in combination with trocar cystoscopy were performed. The catheter was indwelt for an average of 4 weeks (Table 1).

TABLE 1. Cases of cryosurgery

\begin{tabular}{|c|c|c|c|c|}
\hline Patient & $\underset{\text { (years) }}{\text { Age }}$ & $\begin{array}{c}\text { Removal of } \\
\text { catheter } \\
\text { (postoperative } \\
\text { days) }\end{array}$ & Complication & Results \\
\hline FS & 87 & 19 & Epididymitis & TUR, res. urine $8 \mathrm{ml}$ \\
\hline $\mathrm{KS}$ & 80 & 8 & Scrotal edema & Res, urine $14 \mathrm{ml}$ \\
\hline EE & 74 & 14 & - & Res. urine $19 \mathrm{ml}$ \\
\hline SS & 81 & 32 & - & TUR, res. urine $14 \mathrm{~m}$ \\
\hline KK & 68 & - & Enteroparesis, anuria & Died \\
\hline$M G$ & 73 & 40 & - & TUR, res. urine $4 \mathrm{ml}$ \\
\hline To & 71 & 11 & - & Res. urine $30 \mathrm{ml}$ \\
\hline SH & 66 & 30,20 & Pyeronephritis & Res. urine $25 \mathrm{ml}$ \\
\hline TK & 76 & 42 & - & TUR, no Res. urine \\
\hline NS & 73 & 20 & - & No catheterization \\
\hline SI & 86 & 30 & - & Res. urine $25 \mathrm{ml}$ \\
\hline MK & 85 & 30 & - & Res. urine $20 \mathrm{ml}$ \\
\hline OT & 70 & 34 & - & Res, urine $19 \mathrm{ml}$ \\
\hline GH & 73 & - & $\begin{array}{l}\text { Enteroparesis, asthma } \\
\text { bronchiale }\end{array}$ & Died \\
\hline $\mathrm{KS}$ & 75 & - & Heart failure & Died \\
\hline $\mathrm{KU}$ & 72 & 27 & Hemorrhage & Res. urine $25 \mathrm{ml}$ \\
\hline MH & 75 & 20 & Hemorrhage & Res. urine $11 \mathrm{ml}$ \\
\hline To & 82 & 21 & Hemorrhage & No catheterization \\
\hline
\end{tabular}

Postoperative complications consisted of urethral hemorrhage in 3 cases, and epididymitis and scrotal edema in 1 . In Case 15, the patient died of heart failure 3 days after operation, and in Cases 5 and 14 postoperative courses were fatal with enteroparesis. The most serious complication of cryosurgery on the prostate gland which we have hitherto encountered is enteroparesis, and a study is in progress of its mechanism. Most satisfactory results have been achieved in the cases, excluding these fatal ones but including the cases in which TUR (trans urethral resection) was combinedly employed. In Case 9, a large necrotic mass fell off 2 months after cryosurgery; the residual urine then disappeared, and no dysuria has recurred for the past 3 years since then. In Fig. 1 is shown the urethrogram in this case. In Case 12, the residual urine amounted to $20 \mathrm{ml} 3$ years after operation; the measurement of urine flow was normal, and the urethrogram showed a marked dilatation of the posterior urethra. In the other cases, dysuria has been improved, and in all of them, spontaneous urination is possible. Furthermore, in none of the cases under long-term observation the patient felt a further consultation necessary with a complaint of dysuria. 


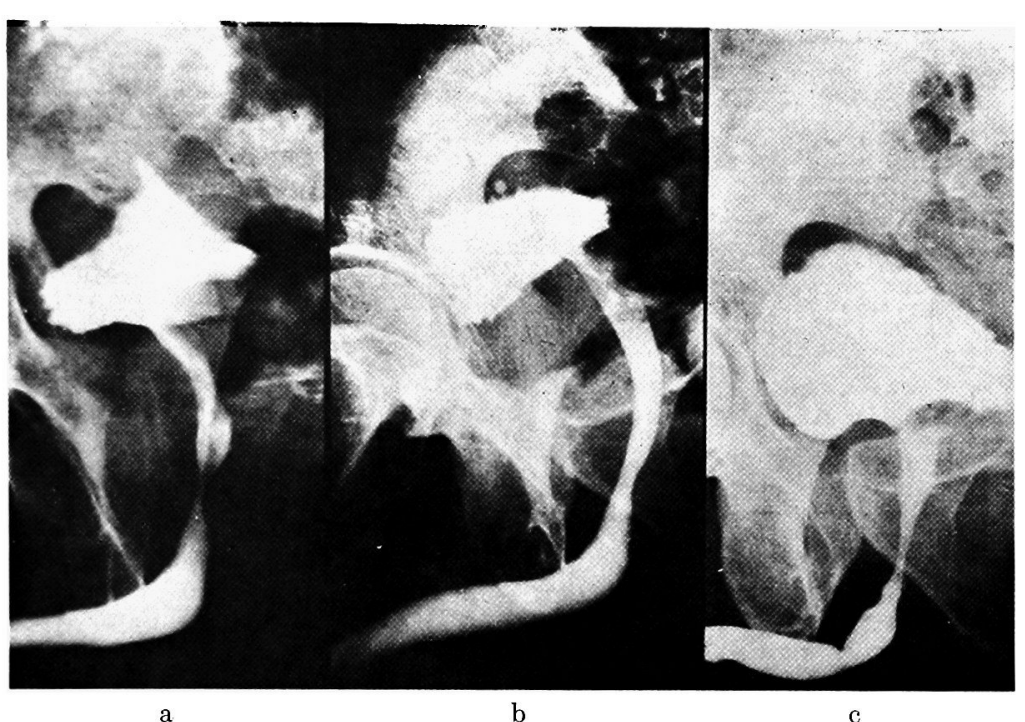

Fig. 1. Vesicourethrogram of Case 9 . a, before operation; b, 2 months after operation; c, 3 years after operation.

\section{Freezing time and freezing index}

In performing cryosurgery on the prostate gland, the frozen area would extend as the freezing time is prolonged. In order to find the relationship between the freezing time and the extent of frozen area, a model experiment was made by the use of devil's-tongue jelly. Pieces of commerically available devil's tongue jelly (with a specific gravity of 1.018) were dipped in warm water in a thermostatic vessel maintained at $37^{\circ} \mathrm{C}$. At the time when even the deep part of each piece of the jelly came to a constant temperature of $37^{\circ} \mathrm{C}$, the tip of the probe was inserted into each piece, and the piece was frozen. The experimental conditions were kept the same as the conditions in which cryosurgery is performed, and the tip of the probe was maintained at -180 to $-190^{\circ} \mathrm{C}$. Immediately after freezing, the surrounding piece of the jelly was removed to leave only an ice ball, which was then weighed (Fig. 2). It was revealed that the weight of the ice ball increased with the lapse of time, there being a linear correlation between the weight of the ice ball and the freezing time in the stage beyond 2 min after the start of freezing (Fig. 3).

From the experimental result, the volume that can be frozen in cryosurgery on the prostate gland, if converted to weight, increases in positive proportion to the freezing time. The following relative equation is obtained from Fig. 3:

$$
y=7.7 t+5
$$

where $y$ is the frozen weight in gram, and $t$ the freezing time in minute.

It was considered that the freezing time should be adjusted with the size of prostate gland, and it was proposed to call the quotient obtained by dividing the 


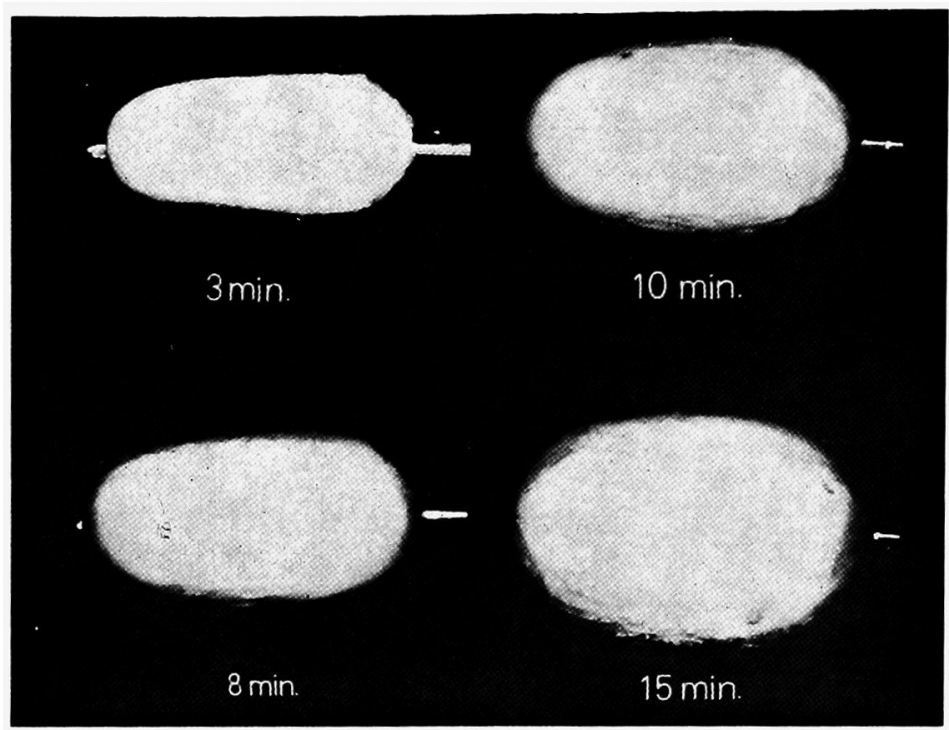

Fig. 2. Freezing time and size of the ice ball.

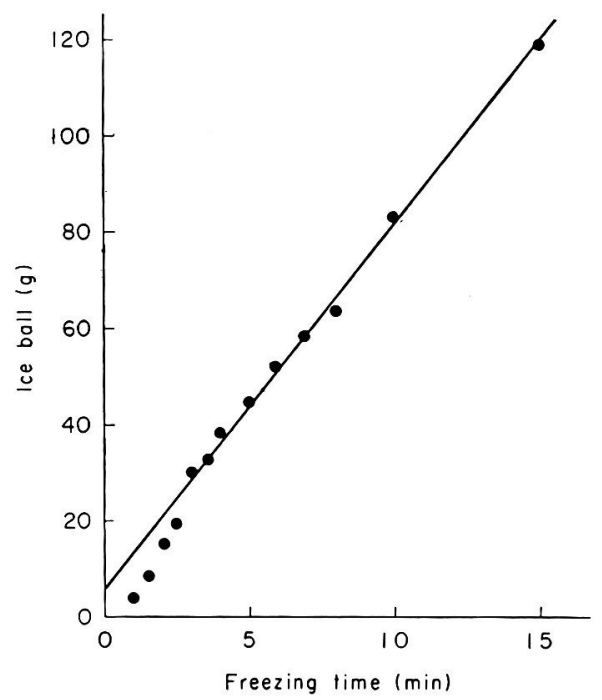

Fig. 3. Freezing time and weight of the ice ball.

presumed prostate gland weight by the frozen weight calculated by the formula according to the freezing time the freezing index, and to use the index as an index to the extent of freezing in cryosurgery on the prostate gland as follows:

$$
\text { Freezing index }(\mathrm{FI})=\frac{\text { estimated weight of hypertrophied prostate gland }(\mathrm{g})}{7.7 t+5}
$$


where $t$ is the freezing time (min) after the beginning of the cyrotherapy.

The weight of prostate gland was estimated from the preoperative urethrocystogram by Thumann's method (1951).

\section{Freezing index and clinical findings}

In the 18 cases which were operated on for prostatic hypertrophy, the freezing time extended from $5 \mathrm{~min}$ to $17 \mathrm{~min}$, the freezing index being $0.13-0.91$.

The result of cryosurgery was evaluated as markedly effective in the cases where dysuria disappeared, and there remained little residual urine postoperatively; as moderately effective in the cases where dysuria was ameliorated but the residual urine remained postoperatively, and as ineffective in the cases where no marked postoperative improvement was achieved compared with the preoperative condition. According to these criteria, the surgery was assessed markedly effective in 6 cases, moderately effective in 7 , and ineffective in 2 , besides the aforementioned 3 fatal cases.

When these clinical findings were divided into three groups according to freezing time of 5-6 $\mathrm{min}, 7-10 \mathrm{~min}$, and not less than $11 \mathrm{~min}$, and the groups were compared with one another, the markedly effective cases were found in all of the three groups, and also the three cases of complications were found in all the three groups (Table 2). In other words, when the freezing was made for not less than 5 min, there appeared no close relationship between the freezing time and the results of cryosurgery.

TABLE 2. Freezing time and results of cryosurgery

\begin{tabular}{ccccc}
\hline $\begin{array}{c}\text { Freezing } \\
\text { time (min) }\end{array}$ & $\begin{array}{c}\text { Markedly } \\
\text { effective }\end{array}$ & $\begin{array}{c}\text { Moderately } \\
\text { effective }\end{array}$ & Ineffective & $\begin{array}{c}\text { Serious } \\
\text { complication }\end{array}$ \\
\cline { 2 - 5 } & 1 & 2 & 2 & 1 \\
$5^{-6}$ & 3 & 4 & 0 & 1 \\
$7^{-10}$ & 2 & 1 & 0 & 1 \\
\hline
\end{tabular}

On the other hand, when the freezing indices were graded into three steps, that is, $0-0.5,0.51-0.75$, and over 0.76 , the markedly effective cases were found in the two groups of $0-0.5$ and $0.51-0.75$, and none in the group of over 0.76 , while the cases where no change was brought about belonged to the two groups of not less than 0.76 and $0-0.5$. All the cases of complications and the fatal cases were found only in the group of $0-0.5$ (Table 3).

In view of these findings, it is doubtless that the results of cryosurgery on the prostate gland are correlated with the freezing index; therefore, a satisfactory effect may be anticipated only if an adequately long freezing time is allowed, compared with the size of the prostate gland. However, a very long freezing time, that is, a very small freezing index is liable to be associated with a high incidence 
TABLE 3. Freezing index and results of cryosurgery

\begin{tabular}{ccccc} 
FI & $\begin{array}{c}\text { Number of cases } \\
\text { Markedly } \\
\text { effective }\end{array}$ & $\begin{array}{c}\text { Moderately } \\
\text { effective }\end{array}$ & Ineffective & $\begin{array}{c}\text { Serious } \\
\text { complication }\end{array}$ \\
\hline $0 \sim 0.5$ & 3 & 2 & 0 & 3 \\
$0.51 \sim 0.75$ & 3 & 3 & 0 & 0 \\
$0.76 \sim$ & 0 & 2 & 2 & 0 \\
\hline
\end{tabular}

of complications, so that it is necessary to take good care in the case of freezing indices not more than 0.5 .

A freezing index, $F I=1$, shows that the freezing weight conforms with the estimated weight of the hypertrophied gland of the prostate, and we call this index limiting freezing index. In this instance, $t$ is the limiting freezing time. When compared with the clinical effects achieved, however, the optimal freezing index calculated empirically was 0.6 , which is lower than the limiting freezing index probably due to the effect that the exfoliating prostate tissue undersized the frozen area that was estimated from the results of the model experiment. This is called the ideal freezing index, and the freezing time in this instance, the ideal freezing time. Even if the ideal freezing index remains invariable, the ideal freezing time varies with the size of the prostate gland, and may be calculated by the following equation:

Ideal freezing time, IFT

$=$ estimated weight of prostate gland $(\mathrm{g}) / 4.62-0.65$.

According to this equation, the ideal freezing time for prostatic hypertrophy with an estimated prostate gland weight of $40 \mathrm{~g}$ may be said to be $8 \mathrm{~min}$.

\section{Discussion}

It is both the freezing temperature and the freezing time that may influence the result of cryosurgery on the prostate gland. The cooling temperature is determined by the refrigerant used. Lately, liquid nitrogen with a boiling point of $-196^{\circ} \mathrm{C}$ is used as a refrigerant, and on the aforementioned $\mathrm{CE}-4$ unit the cooling temperature is controllable with the electrical control system provided at the tip of its probe in the range from $+50^{\circ} \mathrm{C}$ to $-200^{\circ} \mathrm{C}$. According to papers by other authors, they have utilized the maximum freezing temperature at the tip of the probe; that is, $-160^{\circ} \mathrm{C}$ by Dow $(1917),-160^{\circ} \mathrm{C}$ by Marshall et al. $(1973),-170^{\circ} \mathrm{C}$ by Nonaka and Yuzawa $(1971),-160^{\circ} \mathrm{C}$ by Maeda $(1970)$, and $-160^{\circ} \mathrm{C}$ by Matsume et al. (1975). In other words, the freezing temperatures used by them are mostly uniform. It may also be said that many authors have made cryosurgery at the same freezing temperature.

The freezing time, however, varies from author to author, and also varjes from operation to operation even by one and the same author. Hansen et al. (1969) 
described that the freezing time extended over 4-25 min, and that it extended over 5-15 min in most cases. Reuter (1972) showed that the freezing was accomplished in 1-6 min in 329 cases, accounting for $94 \%$ of all the cases operated on by cryosurgery, and in 7-10 min in other cases. A freezing time less than 7 min was described by Marshall et al. (1973), 6-25 min with an average of $16 \mathrm{~min}$ by Nonaka and Yuzawa (1971), 5-12 min by Maeda (1970), 3-7 min with an average of $6 \mathrm{~min}$ by Natsume et al. (1975), 4-7 $\mathrm{min}$ by Itoh et al. (1975), and $48 \mathrm{~min}$ by Nagahara et al. (1975). These authors appear to have varied the freezing time in different cases; however, in view of this large variation, there appears to be no established freezing time. There are, on the other hand, some authors discussing the target freezing time. Dow et al. (1970) described that freezing was discontinued at the time when the capsule temperature dropped to $-15^{\circ} \mathrm{C}$, and Nonaka and Yuzawa (1971) showed that, as the criterion for the freezing time, a thermister needle was inserted into the rectal submucosa, and the freezing was regarded as complete when the temperature in the rectal submucosa dropped to $-10^{\circ} \mathrm{C}$. As is described by Nonaka and Yuzawa (1971), however, this method is not stable in respect to the insertion of the thermister needle, and therefore appears to be accompanied by difficulty in measuring accurate temperature, because even a slight deviation in the position of the needle results in a difference in measured temperature. When the freezing times presented in the aforementioned papers are reviewed, there appear to be two groups of authors, that is, a group of authors limiting the freezing time uniformly within 6-7 min, and a group positively varying the freezing time with the size of the prostate gland, the time even extending over about $20 \mathrm{~min}$ in some cases. The former probably takes the point of view that cryosurgery aims at nothing but improvement in dysuria, and because this is achieved by dilating only a small portion of the prostatic urethra, freezing of 6-7 min is already sufficient. The latter appears to aim at such an effect which may be compared to that of prostatectomy by means of freezing such a volume which is comparable to the whole amount of hypertrophied gland of the prostate.

From the point of view that cryosurgery on the prostate gland is a mere makeshift approach to poor risk patients, we currently consider that the primary aim of this approach will be achieved if only dysuria is managed. However, it is more desirable to freeze a wider area within a safe limit if possible, and this has necessitated the setting of such a freezing time which varies with the size of the prostate gland. According to our method described in the present paper, it is possible to obtain the ideal freezing time from the estimated weight of the hypertrophied gland of the prostate at any time, if only the relationship between the size of the ice ball and the freezing time has been examined beforehand with the freezing unit to be used. In our present study, the ideal freezing index that was achieved empirically was lower than the limiting freezing index $(\mathrm{FI}=1)$, but this may be considered attributable to the discrepancy between the volumes of frozen area and the area that fell off postoperatively. In other words, FI=1 means that 
the whole hypertrophic gland is frozen (on the assumption that the prostate gland in situ is frozen with a velocity similar to that with which devil's tongue jelly is frozen); however, since it is only in the case where the tissue is collected below $-15^{\circ} \mathrm{C}$ that necroses are produced due to coldness (Dow et al. 1970), necrotic foci are smaller than the frozen area. In order to achieve a satisfactory effect, it is necessary to freeze beyond $F I=1$, and we consider that the ideal freezing index will therefore be 0.6 .

\section{References}

1) Dow, J.A. (1971) The technique of cryosurgery of the prostate. J. Urol., 105, 286-290.

2) Dow, J.A., Coughlin, J.D. \& Waterhouse, K. (1970) Lethal freezing temperatures of the surgical capsule and cryosurgery of the prostate. J. Urol., 104, 459-462.

3) Gonder, M.J., Soanes, W.A. \& Shulman, S. (1966) Cryosurgical treatment of the prostate. Invest. Urol., 3, 372-378.

4) Itoh, M., Tsuchiya, M., Fukami, M., Miyakawa, M. \& Kuze, M. (1975) Cryosurgery in the treatment of prostatic obstruction: Part 1. Acta urol. jap. (Japanese), 21, $67-78$.

5) Hansen, R.I., Lund, F. \& Backer, O.G. (1969) Cryosurgery of the prostate. Urol. Int., 24, 160-165.

6) Maeda, K. (1970) Cryosurgery of the prostate. Nishinihon J. Urol. (Japanese), 32, $242-254$.

7) Marshall, A., Brown, A.K., Jones, W.W. \& Lindsay, R.M. (1973) An assessement of cryosurgery in the treatment of prostatic obstruction. J. Urol., 109, 1026-1028.

8) Nagahara, A., Kohri, K., Osafune, M. \& Kasai, M. (1975) Cryoprostatectomy. Jap. J. clin. Urol. (Japanese), 29, 407-413.

9) Natsume, H., Murase, T., Honda, N., Obata, K. \& Mitsuya, H. (1975) Experience of cryosurgery of the prostate. Nishiniton $J$. Urol. (Japanese), 37, 883-887.

10) Nonaka, H. \& Yuzawa, J. (1971) Cryosurgery of the prostate. Shujutsu (Japanese), 25, 313-320.

11) Reuter, H.J. (1972) Endozcopic cryosurgery of prostate and bladder tumors. $J$. Urol., 107, 389-393.

12) Thumann, R.C. (1951) Estmation of the weight of the hyperplastic prostate from the cystoureth ccgram. Amsr. J. Roentgen., 65, 593-595. 